\title{
Treatment of Primary Hyperoxaluria
}

\author{
C. E. DENT and T. C. B. STAMP \\ From University College Hospital, London
}

\begin{abstract}
Dent, C. E., and Stamp, T. C. B. (1970). Archives of Disease in Childhood, 45, 735. Treatment of primary hyperoxaluria. Nine patients with primary hyperoxaluria have been followed regularly for 1 to 11 years, and their treatment and progress are discussed in relation to the known natural history of the disease. 6 of them probably have the usual form of primary hyperoxaluria associated with increased glycollic acid excretion, while 3 who are sibs have the recently described variant associated with L-glyceric aciduria and normal glycollic acid excretion.

All 9 patients have been on regimens designed to increase the urinary solubility of calcium oxalate, with or without the simultaneous lowering of urinary calcium and raising of urinary phosphate excretions. 8 patients have been treated for $1 \frac{1}{2}-7 \frac{1}{2}$ years (average duration 4 years) with oral magnesium hydroxide, and 2 patients have been treated with sodium phosphate. One of the latter was changed after $3 \frac{1}{2}$ years to magnesium hydroxide and the other has been on sodium phosphate combined with a low calcium diet and cellulose phosphate continuously for $5 \frac{1}{2}$ years. 2 , not at first diagnosed as hyperoxalurics, were first given sodium bicarbonate for their presumably secondary renal tubular acidosis.

The over-all progress of the whole group is felt to have been better than could be expected from the known natural history of primary hyperoxaluria. They average $4 \frac{1}{4}$ years on treatment during 5 years of our observation and all remain clinically well after an average of $9 \frac{1}{2}$ years since the onset of their first symptoms. Results warrant the recommendation that, until reliable means are available to decrease oxalate overproduction, affected patients should be treated continuously with magnesium hydroxide. A more final opinion must await many more years of follow-up.

The failure of several attempts to lower urinary oxalate excretion in these patients is also reported.
\end{abstract}

Primary hyperoxaluria is an inborn error of metabolism in which there is excessive production and urinary excretion of oxalate. The disease usually presents with calcium oxalate lithiasis in early childhood and runs a progressive course leading to death from renal failure with oxalosis before adult life (Hockaday et al., 1964). More rarely milder cases presenting in late adolescence can also occur.

Therapy has proved disappointing and no effective general recommendation exists. Attempts at treatment have been directed either toward inhibition of oxalate synthesis and thus of oxalate excretion or towards decreasing the tendency to crystallization of calcium oxalate in urine. The latter aim has offered three possible approaches.

Received 8 June 1970.
Firstly, the presence of magnesium has long been known to inhibit the quantitative precipitation of calcium salts in vitro, and this has raised the possibility of promoting its urinary excretion by treatment with oral magnesium compounds. Secondly a high phosphate intake has been thought to be of value in renal stone formation, partly by decreasing calcium excretion and partly by increasing urinary pyrophosphate, but the basic mechanism remains uncertain (Howard and Thomas, 1968). Thirdly urinary calcium excretion can be decreased by decreasing intestinal absorption. Such studies require long-term follow-up before any evidence is obtained of their true value.

We report here the history and follow-up of 9 patients with primary hyperoxaluria, 8 of them treated for 1 to 7 years with magnesium hydroxide and 2 of them treated with a low calcium intake and 
sodium phosphate, one for $3 \frac{1}{2}$ years before changing this for magnesium and the other for 5 years coupled with cellulose phosphate to reduce intestinal calcium absorption.

\section{Methods and Patients Studied}

Standard laboratory methods were used except for urinary oxalate. Before 1965 this was determined by various means by colleagues elsewhere. From 1965 the method of Dick (1967) was used. The normal 24-hour urinary oxalate output is 3-22 mg., as determined by any of these methods.

Case 1. (Peter T.) Born October 1955, the eldest of 3 affected sibs, his birth and early development were normal. His parents are unrelated.

At the age of 23 months he developed haematuria followed by brief anuria. A stone was removed from the urethral meatus, and he passed a second stone. $\mathrm{He}$ remained well after this episode, but 7 months later he was found to have a urinary infection with $B$. proteus.
When first admitted to U.C.H. in July 1958 at the age of 2 years 9 months physical examination was normal, and his height was on the 50th centile. Investigations at that time showed $\mathrm{Hb} 11.5 \mathrm{~g} . / 100 \mathrm{ml}$.; plasma urea and electrolytes were normal apart from a bicarbonate level of $21.4 \mathrm{mMol} / 1$. , and plasma calcium, phosphorus, and alkaline phosphatase were also normal. Urine examination showed persisting infection with $B$. proteus. 24-hour calcium excretion was $49 \mathrm{mg}$. and an amino acid chromatogram was normal. 24-hour oxalate excretion was recorded at only $22 \mathrm{mg}$.; however, after a divided oral load of sodium oxalate $140 \mathrm{mg}$., his simultaneous 24-hour oxalate excretion increased to $42 \mathrm{mg}$. Radiology revealed bilateral renal stones and a staghorn calculus on the right side. He was able to acidify his urine to a minimum $p \mathrm{H}$ of $5 \cdot 2$ after an ammonium chloride load. His urinary infection was successfully treated with sulphonamides and he was discharged on long-term sulphonamide therapy. At that time it was thought that a metabolic cause for his stones had been excluded. At the end of 1958 the right staghorn calculus was

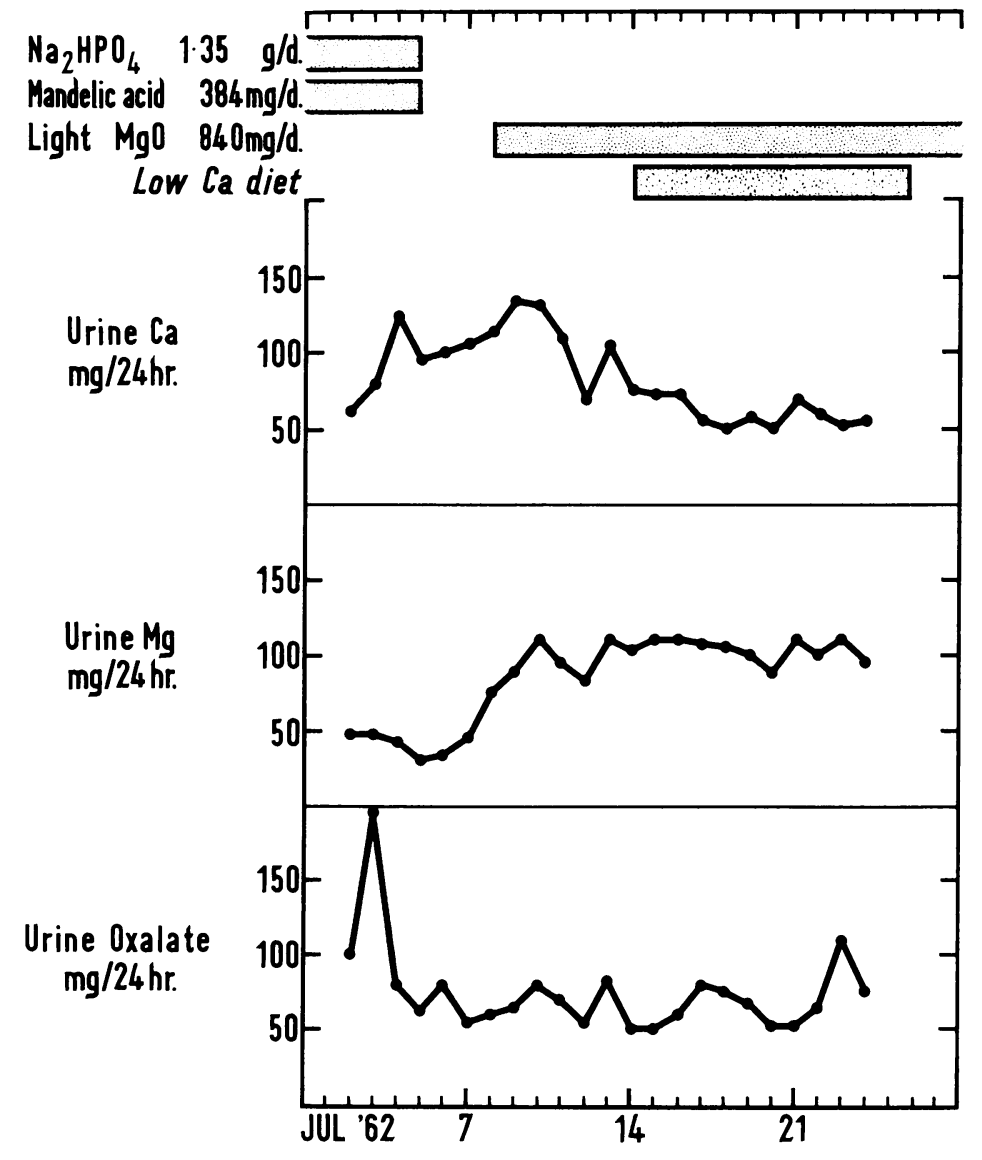

Fig. 1.-Case 1. (Peter T.) 24-hour excretions of calcium, magnesium, and oxalate under various treatments. 
removed surgically, and he was then treated with mandelic acid and sodium acid phosphate until July 1962. He had a single attack of renal colic in October 1961 , but radiology showed no evidence whatsoever of persisting renal calculi.

He was readmitted to U.C.H. in July 1962 aged 6 years 9 months for reappraisal after the discovery that his sister (Case 2), born in November 1958, had hyperoxaluria. He was well and had grown up to the 75th centile. Blood and urine investigations revealed no abnormality except his 24-hour urine oxalate excretion which ranged between 50 and $196 \mathrm{mg}$. Radiology showed a small stone in the left kidney. Previous medication was stopped, and treatment was begun with light magnesium oxide $210 \mathrm{mg}$. daily; for a short time a low calcium diet was also given. Fig. 1 shows his urinary excretion of calcium, magnesium, and oxalate during this admission. It illustrates the typical rise in urinary magnesium which occurs when oral magnesium is given, and also shows the effect of a low calcium diet on reduction of urinary calcium. Urinary oxalate does not change notably and continues to fluctuate widely. $\mathrm{He}$ was discharged for long-term follow-up on magnesium hydroxide mixture (B.P.) $4 \mathrm{ml}$. q.i.d. as sole treatment.

He has remained well since then apart from a few mild episodes of haematuria in 1964 associated with a small additional stone in the left ureter which subsequently disappeared. Further $x$-rays have shown no change (Fig. 2a and b). His growth rate has gradually returned to the 50th centile.

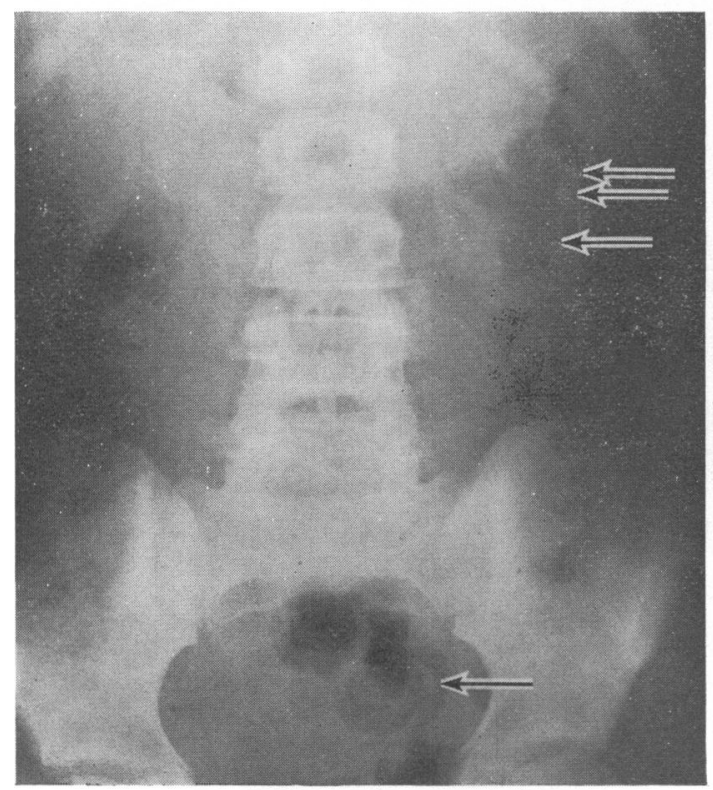

(a)

FIG. 2.-Case 1. (Peter T.) X-rays of renal areas (a) 1 June 1964: 3 small calcified deposits are seen in the left kidney and one in the line of the lower left ureter. (b) 15 September 1969: only one small stone is now visible in the left kidney.

Case 2. (Gillian T.) Born November 1958, was the sister of Case 1. Her birth and early development were normal.

At the age of $2 \frac{1}{2}$ she developed haematuria and passed a small stone. Radiology revealed bilateral nephrocalcinosis, and additional large calculi at the lower ends of both ureters were removed surgically.

When first admitted to U.C.H. in June 1962 at the age of 2 years 7 months she was well and had had no further urinary episodes. She had suffered excessive thirst all her life, drinking as much as 2 litres daily. Physical examination showed no abnormality; however her height was on the 3rd centile and her weight was below the 3 rd centile. Investigations at that time showed $\mathrm{Hb} 12 \cdot 2 \mathrm{~g} . / 100 \mathrm{ml}$., plasma urea and electrolytes were normal apart from a total bicarbonate of 20.5 mMol./l., plasma calcium, phosphorus, magnesium and alkaline phosphatase were also normal. Urine examination showed numerous pus cells but was sterile. Creatinine clearance was $21 \mathrm{ml} . / \mathrm{min}$. $(73 \mathrm{ml} . / \mathrm{min}$. per 1.73 sq. m.), 24-hour calcium excretion was $30-38 \mathrm{mg}$., magnesium $24 \mathrm{mg}$., and an amino acid chromatogram was normal. 24-hour oxalate excretion ranged between $40-60 \mathrm{mg}$. After an oral ammonium chloride load $(0.1 \mathrm{~g} . / \mathrm{kg}$. body weight $)$ her urine $p \mathrm{H}$ fell to a minimum of only $5 \cdot 6$, and secondary renal tubular acidosis was diagnosed. Radiology revealed severe calcification of the renal pyramids, with a stone lying in the lower half of the left kidney; the kidney size was normal.

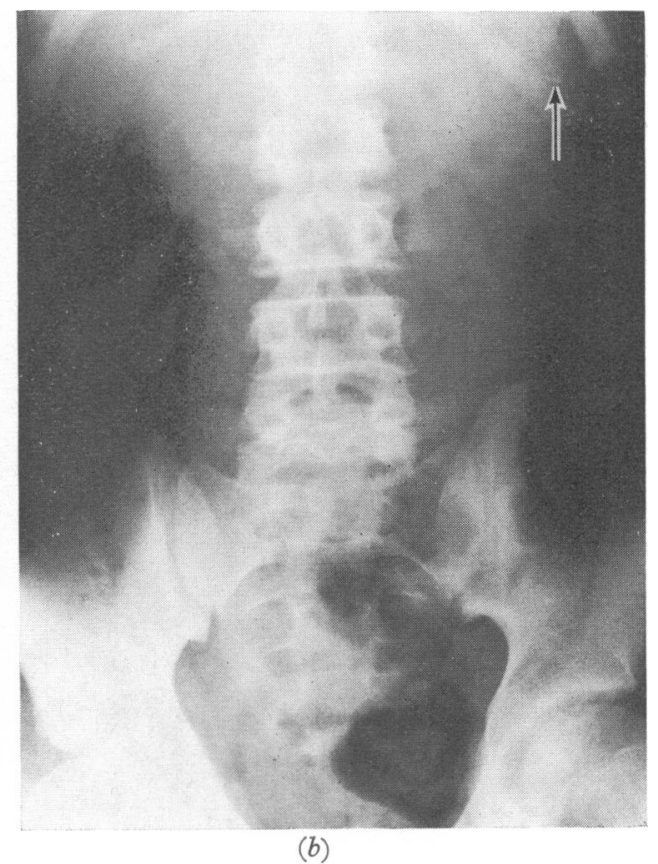


She was given a low calcium diet and treated with light magnesium oxide $210 \mathrm{mg}$. daily. On this regimen, 24-hour urinary calcium excretion remained below $40 \mathrm{mg}$. and magnesium excretion rose from a mean of $24 \mathrm{mg}$. to a mean of $68 \mathrm{mg}$.

A calcium balance study during this regimen showed a mean positive balance of $30 \mathrm{mg}$. daily. She was discharged for long-term follow-up taking only mandelic acid 1 g. q.i.d. (as neutral calcium mandelate) and sodium bicarbonate $1 \mathrm{~g}$. t.d.s.

Since then she has remained clinically well. However, the radiological appearances continued to deteriorate slowly, and in view of the hopeful results being obtained with other similar patients she was started in August 1965 (aged 6 years 9 months) on magnesium hydroxide mixture (B.P.) $4 \mathrm{ml}$. q.i.d. instead of her previous medication. Her nephrocalcinosis has nevertheless increased slowly, and in September 1969 she was restarted on sodium bicarbonate $1 \mathrm{~g}$. t.d.s. as additional treatment for her renal tubular acidosis (Fig. 3a-c) as it seemed possible that it was this latter complication that was now the cause of the continuing deterioration. Plasma urea, electrolytes, urate, and creatinine have remained normal. Her height has grown up to between the 10th and 25th centile, and her weight has increased to between the 3rd and 10th centile.

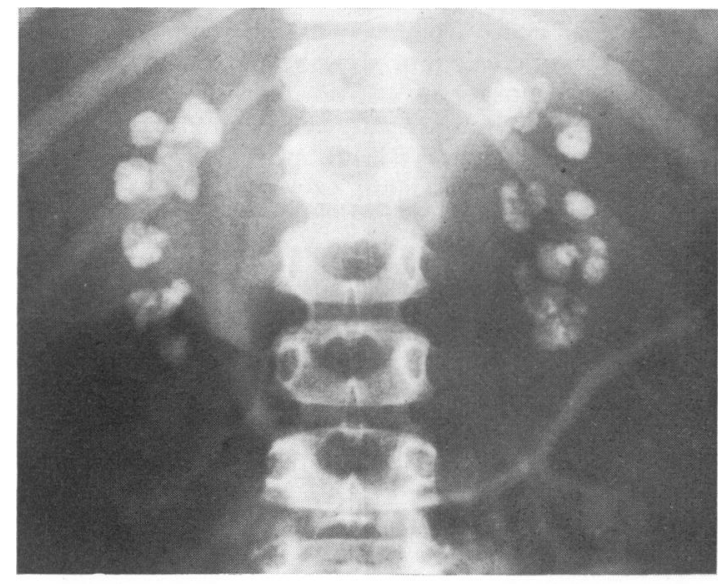

(a)

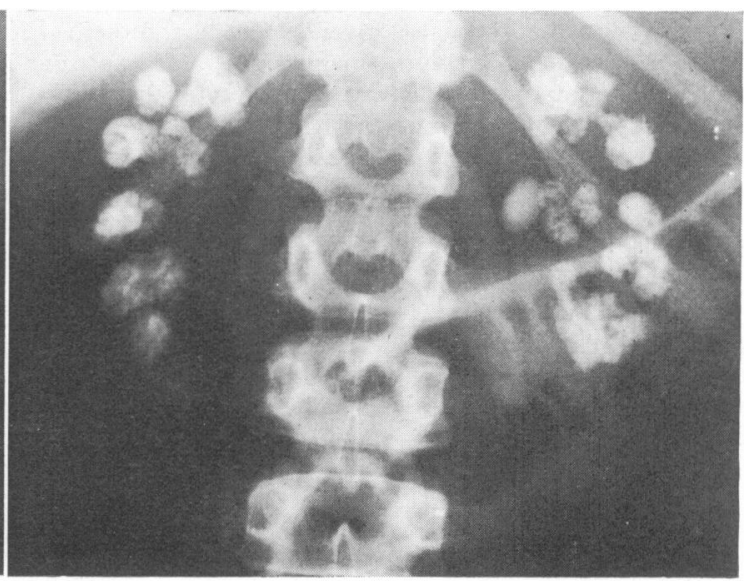

(b)

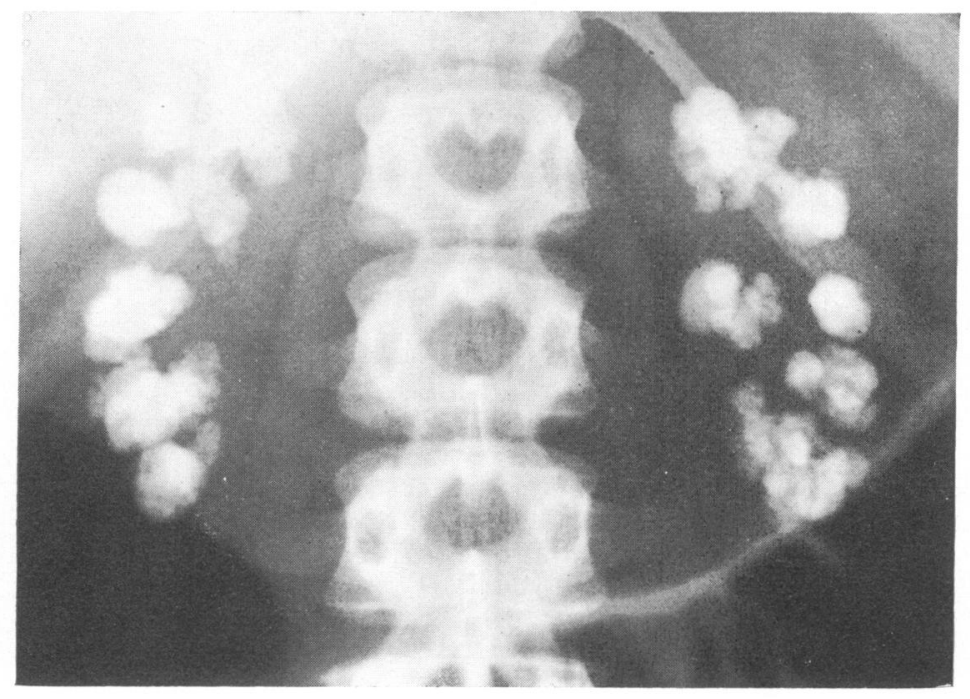

(c)

FIG. 3.-Case 2. (Gillian T.) X-rays of renal areas. (a) 12 June 1962: generalized papillary nephrocalcinosis is seen. (b) 2 August 1965: the kidneys have grown but the nephrocalcinosis is worse. (c) 15 September 1969: further growth of kidneys is noted in spite of more marked calcinosis. 
Case 3. (Christopher T.) Born March 1965, he is the younger brother of Cases 1 and 2. His birth and postnatal development were normal.

He was first seen at U.C.H. in August 1965 aged 5 months, when physical examination was normal. His height was on the 50 th centile, and his weight just above the 90th. Investigation at that time showed $\mathrm{Hb}$ $11.5 \mathrm{~g} . / 100 \mathrm{ml}$., plasma levels of calcium, urea, and electrolytes were normal. Urine examination showed no abnormality apart from numerous oxalate crystals; the 24-hour urine calcium excretion was 30-37 mg., and oxalate excretion 32-34 $\mathrm{mg}$. Radiology revealed 3 small areas of calcification in the left kidney.

On thus confirming the expected diagnosis treatment was begun with magnesium hydroxide (B.P.) $2 \mathrm{ml}$. q.i.d. and he was discharged for long-term follow-up. Between December 1965 and January 1966 he passed several stones and suffered haematuria, but has remained well since that time, with the exception of several days

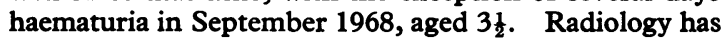
shown minimal enlargement of one left renal stone.
Plasma urea, electrolytes, urate, and creatinine levels remain normal.

Case 4. (Robert C.) Born September 1955, the 3rd child of unrelated parents, his birth and early development were normal, and there was no relevant family history.

At the age of 2 years 7 months he developed persistent haematuria and passed 3 stones, the attack resolving in about 2 days. At the age of 3 years exactly he developed acute anuria requiring the removal of 12 stones from his urethra. He had no other symptoms. Investigation at that time revealed bilateral nephrocalcinosis.

When first admitted to U.C.H. in July 1959 at the age of 3 years 10 months, physical examination revealed no abnormality apart from mild knock-knees; his height and weight were on the 50th centile. All blood investigations at that time were interpreted as normal. Urine examination showed no protein, variable numbers of red and white cells, and the presence of calcium oxalate crystals, and was sterile on culture. 24-hour calcium

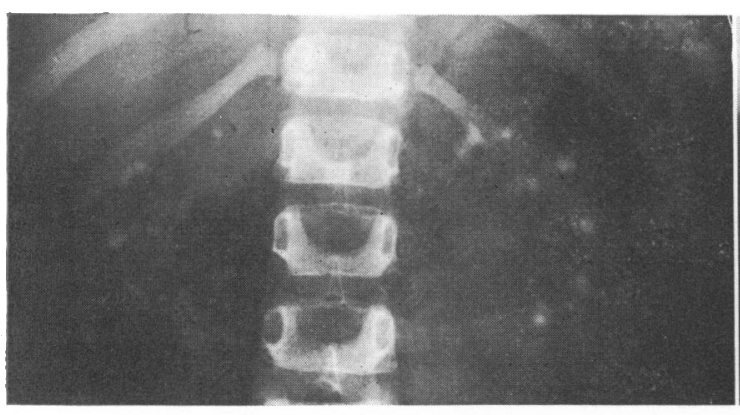

(a)

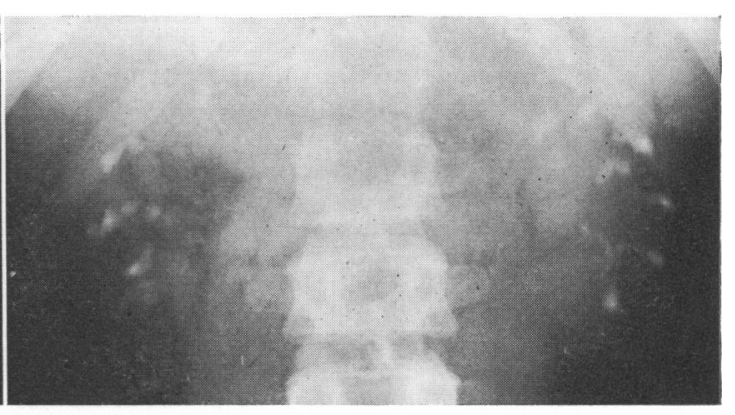

(b)

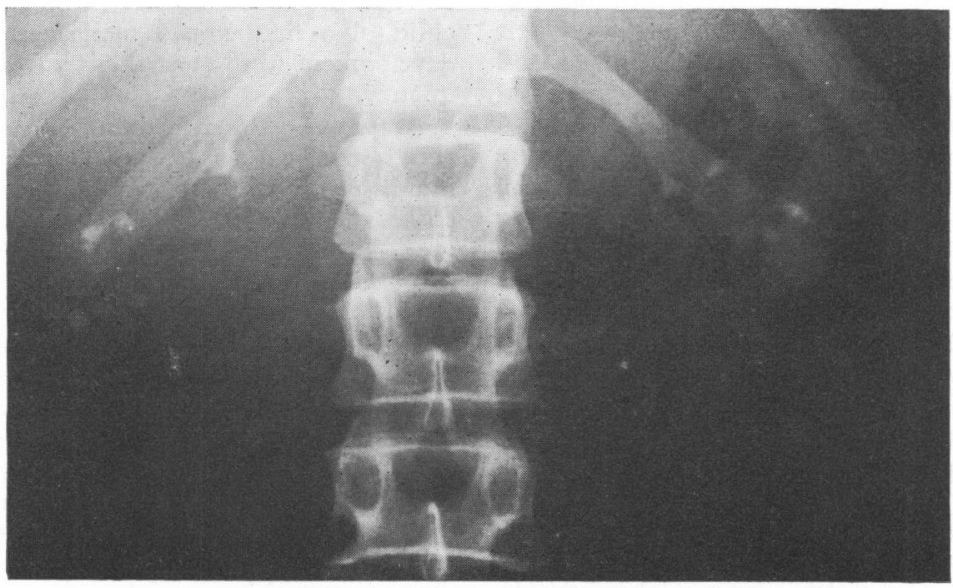

(c)

FIG. 4.-Case 4. (Robert C.) X-rays of renal areas. (a) 29 March 1960: generalized papillary nephrocalcinosis is seen. (b) 12 June 1967: perhaps the calcified masses are larger than in 1960. (c) 11 August 1969: the nephrocalcinosis seems a little less than in 1967. Good increase in kidney size is shown by the increasing separation of the calcified papillae over the years. 
excretion was 106-113 mg. and an amino acid chromatogram was normal. Radiology revealed extensive calcification in both kidneys. After an oral ammonium chloride load $(0 \cdot 1 \mathrm{~g} . / \mathrm{kg}$. body weight) his urine $p \mathrm{H}$ fell to only 5.6 and there was no increase in ammonium excretion. A tentative diagnosis of a renal tubular acidosis was thus made. He was started on sodium bicarbonate 1 g. q.i.d., and after this his 24-hour urine calcium excretion fell to 52-60 mg.

Treatment with sodium bicarbonate was continued and long-term follow-up begun. He remained well with no appreciable changes in the results of his investigations until March 1964 at the age of 8 years 6 months when his renal calcification was found to be increasing. Four months later his urinary oxalate excretion was determined and found to be $47 \mathrm{mg} . / 24$ hours, and the correct diagnosis of primary hyperoxaluria was established. His nephrocalcinosis progressively deteriorated until June 1967 when he was begun on magnesium hydroxide mixture (B.P.) $4 \mathrm{ml}$. q.i.d. in addition to his sodium bicarbonate. Since that time his radiological changes have not progressed. Throughout the whole period of his follow-up he has remained well, with only one mild episode of haematuria in the early months, and has grown well up to and just above the 75th centile in height. His urine has always contained variable numbers of red and white blood cells, with not more than a trace of protein and his plasma urea is $29 \mathrm{mg} . / 100 \mathrm{ml}$.

Case 5. (Noel D.) Born January 1950, the 3rd child of unrelated parents, his birth and infancy were normal. There is no relevant family history. At the age of 20 months he first passed a small calculus and was treated with antibiotics. At the age of 3 he passed a further stone, and radiology revealed bilateral renal calculi. By August 1956 he had been suffering frequent attacks of renal colic for 9 months, and finally underwent left nephrolithotomy at which a stone the size of a small cherry was removed. A right renal stone was removed in 1959. In 1961 he was treated with isoniazid for 9 months after the demonstration of a positive Mantoux test. During 1962 and 1963 he was passing calculi spontaneously every 2-4 weeks and suffering frequent attacks of haematuria. He underwent a third operation in November 1963 in which a stone the size of a chestnut was removed from his left kidney in addition to 2 smaller calculi, and about $15 \mathrm{~g}$. kidney tissue was amputated. However colic, haematuria, and the passage of stones continued at intervals of 3 to 4 weeks.

He was first seen at U.C.H. in March 1964 at the age of 14. He was well apart from his urinary symptoms and physical examination revealed only his previous surgical scars. His blood pressure was $120 / 60 \mathrm{~mm}$. $\mathrm{Hg}$ and his height and weight were normal for his age. Investigations at that time showed normal haemoglobin, plasma urea, and electrolytes, urate, calcium, phosphorus, and alkaline phosphatase. Urine examination showed a trace of protein, 3 to 5 white and 8 to 10 red blood cells per high power field, and was sterile on culture. The overnight urine specific gravity was 1020 and the urine diluted after a waterload to a specific gravity of 1003 . 24-hour calcium excretion was $74 \mathrm{mg}$. and an amino acid chromatogram was normal. The 24 -hour oxalate excretion was $135-222 \mathrm{mg}$. Radiology revealed a generally dense skeleton and dense bilateral renal calculi.

Successive short trials were performed with oral D-L glutamic acid $20 \mathrm{~g}$. daily, and disodium hydrogen phosphate $10 \mathrm{~g}$. daily, but no effect on the 24-hour urinary oxalate excretion was seen. He was finally begun on a low calcium diet ( $400 \mathrm{mg}$. daily) with cellulose phosphate 5 g. t.d.s. which produced a satisfactory fall in calcium excretion from 75-200 $\mathrm{mg}$. to $42-57 \mathrm{mg}$. He was discharged for long-term follow-up on this regimen which included a 3-litre fluid intake, and two months later disodium hydrogen phosphate $2 \mathrm{~g}$. 5 times daily was added.

His clinical progress during the 6-year follow-up has shown an obvious improvement. In spite of a few setbacks he has been especially active physically, sailing in the summer and skiing and mountaineering. $\mathrm{He}$ underwent left ureterolithotomy in November 1965 after the progressive slight enlargement of a single stone. Since that time he has passed only 2 stones and radiology has shown no change apart from questionable minimal enlargement of calculi on the right side. He has noticed occasional haematuria over a short period in 1966, and again in 1969 accompanied by colic before the passage of one stone. Plasma electrolyte, urea, calcium, and phosphorus levels have remained normal throughout. Plasma urate levels have risen from $5.3 \mathrm{mg} . / 100 \mathrm{ml}$. in 1967 to $8.3 \mathrm{mg} . / 100 \mathrm{ml}$. in $1968 / 69$. He has also shown an unexplained polycythaemia with haemoglobin levels up to $18.7 \mathrm{~g} . / 100 \mathrm{ml}$. (16.5 g. $/ 100 \mathrm{ml}$. at present). Skeletal $x$-rays have shown good growth and maintenance of bone density.

Case 6. (Neil T.) Born August 1957, the second child of a first cousin marriage, his birth and early development were normal apart from fretful episodes in infancy.

At the age of 2 years 6 months he developed haematuria and abdominal pain, and a stone was demonstrated radiologically in the right ureter. The stone was later passed. He had further pain and haematuria the same year and a left ureteric calculus was passed which consisted of pure calcium oxalate. Between the ages of 5 and 8 he had at least 5 attacks of colic or haematuria and the passage of a stone was demonstrated clinically or radiologically on three separate occasions. He had been treated since 1960 on a low calcium and low oxalate diet.

When first admitted to U.C.H. in August 1965 aged 8 years exactly, physical examination was normal except for his blood pressure of $130 / 100 \mathrm{~mm}$. $\mathrm{Hg}$. His height was on the 97th centile, and his weight between the 90th and 97th centiles. Investigations at that time showed normal haemoglobin, plasma urea, and electrolytes, calcium, phosphorus, and phosphatase. Urine examination showed a trace of protein, occasional red and white blood cells, and was sterile. 24-hour calcium excretion was 38-72 mg., and an amino acid chromatogram was normal. 24-hour oxalate excretion ranged 
from 72-150 mg. Radiology revealed a stone at the lower end of the left ureter which he passed during his admission.

He was treated for a short period with cellulose phosphate 5 g. t.d.s. which negligibly lowered his urine calcium excretion, and for two days with malonate 0.5 g. t.d.s. and 1.0 g. t.d.s., during which his oxalate excretion was unchanged at 78 and $127 \mathrm{mg}$., respectively. $\mathrm{He}$ was discharged for long-term follow-up taking magnesium hydroxide mixture (B.P.) $4 \mathrm{ml}$. q.i.d.

He has remained well since then apart from a transient attack of haematuria early in 1967. His blood pressure is $110 / 70 \mathrm{~mm}$. Hg. His height has grown along the 97th centile. His urinary tract has remained clinically normal and radiologically free from stones.

Case 7. (Neil M.) Born December 1963, the fourth child of unrelated parents, his birth and early development were normal, and there was no relevant family history.

At the age of 11 months he developed haematuria, and at the age of 2 years precisely 3 large stones in the right kidney and 1 large stone in the left renal pelvis were demonstrated radiologically. The left stone was removed and found to consist of pure calcium oxalate. During the subsequent 4 months he had intermittent haematuria and one severe attack.

When first admitted to U.C.H. in May 1966 aged 2 years 5 months he appeared well, and physical examination showed no abnormality apart from his healed surgical scar. His height and weight were both between the 25 th-50th centiles. Investigations at that time showed normal haemoglobin, urea, and electrolytes, urate, calcium, phosphorus, and alkaline phosphatase. Urine examination showed a trace of protein, occasional white and numerous red blood cells, and was sterile. 24-hour calcium excretion was 31-81 $\mathrm{mg}$., and an amino acid chromatogram was normal. 24-hour oxalate excretion ranged between 17-107 mg. Radiology revealed 3 large stones in the right kidney.

$\mathrm{He}$ was treated alternatively with neomycin $0.25 \mathrm{~g}$. q.i.d., given to see if this would effect a constancy of the oxalate excretion, citric acid $10 \mathrm{~g}$. daily, magnesium hydroxide mixture, $4 \mathrm{ml}$., t.d.s., and valine $6 \mathrm{~g}$. daily. No notable changes in the 24-hour urinary output of calcium, magnesium, or oxalate occurred except in his magnesium excretion while taking magnesium hydroxide. He remained well during his admission and was discharged for long-term follow-up taking magnesium hydroxide (B.P.) $3 \mathrm{ml}$. q.i.d.

He has remained clinically well since then with no further attacks of haematuria and no abdominal pain referable to his urinary tract. The right renal stones have remained unaltered in size (Fig. 5a and b). However, since the end of 1969 urine examination has revealed a persistent infection with $B$. proteus, and surgical removal of his renal stones is being contemplated. His height and weight have continued to grow between the 25 th and 50 th centiles.

Case 8. (John M.) Born August 1945 the only child of unrelated parents, his childhood and early adolescence were normal. His father had a single attack of renal colic aged 20 but does not have primary hyperoxaluria.

He had his first attack of renal colic at the age of 17, and thereafter passed 3 or 4 stones a year until treatment was begun. One month before his 20th birthday an intravenous pyelogram performed after an attack of right renal colic showed multiple calculi in the right kidney, and a single calculus in the left. He underwent left ureterolithotomy aged 21 after an attack of left renal colic. Renal colic recurred, and further radiology showed an increase in the size of a right renal calculus. He continued to pass stones though his general health remained good.

He was first admitted to U.C.H. in November 1967 aged 22, and physical examination revealed no abnormality other than his surgical scar. His height was $175 \mathrm{~cm}$., weight $61 \mathrm{~kg}$., and his blood pressure was $125 / 70 \mathrm{~mm}$. $\mathrm{Hg}$. Investigations at that time showed normal levels of haemoglobin, plasma urea, electrolytes,

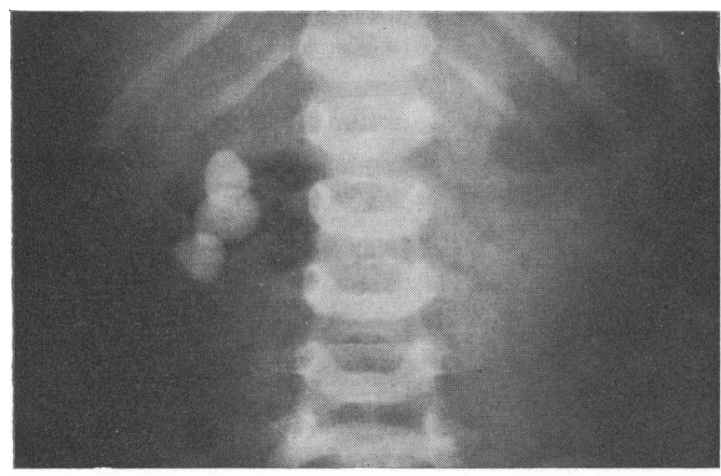

(a)

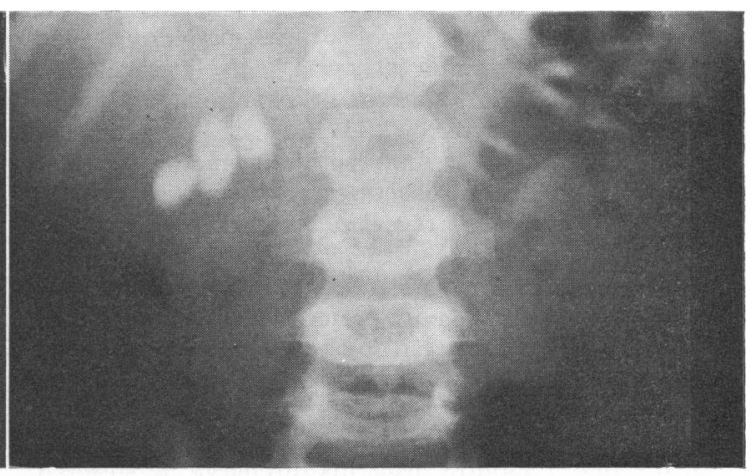

(b)

FIG. 5.-Case 7. (Neil M.) X-rays of renal areas. (a) 16 December 1966: three large opaque stones are seen in the right renal pelvis. (b) 23 June 1969: the three stones, blurred from movement, are seen to be no larger than nearly 3 years ago. 
urate, calcium, phosphorus, magnesium, and alkaline phosphatase. Urine examination showed no protein, occasional white and 8 to 10 red blood cells per high power field, and was sterile. 24-hour urine calcium excretion was $164 \mathrm{mg}$., magnesium $116 \mathrm{mg}$., and amino acid chromatogram was normal. 24-hour oxalate excretion ranged from 57 to $97 \mathrm{mg}$. Radiology revealed bilateral small dense stones.

Therapy was attempted first with pyridoxine $100 \mathrm{mg}$. 5 times daily, then with disulfiram $500 \mathrm{mg}$. b.d., and then with calcium carbimide $50 \mathrm{mg}$. b.d. No significant change occurred in his oxalate excretion during this time. He was discharged for long-term follow-up taking magnesium hydroxide mixture (B.P.) $10 \mathrm{ml}$. b.d.

Since then in the past 2 years he has painlessly passed two stones and has remained well in himself. In October 1968 radiology revealed a new stone in the upper left ureter, but in November 1969 this was no longer visible and his other stones have remained unchanged. His blood chemistry remains normal.

Case 9. (John H.) Born September 1958 the only child of unrelated parents, delivered by full-term caesarean section, his early development was a little retarded. He crawled at 1 year and first walked at 2 . There is no relevant family history. Aged 2 years 3 months he suffered a transient hemiplegia after a single convulsion. At the age of 4 years and 9 months he developed dysuria followed after 5 days by retention of urine due to a stone in the urethra which required removal. Radiology of the renal tract showed no abnormality. He remained well until the age of 9 years 8 months when he developed renal colic, and an intravenous pyelogram showed bilateral renal and ureteric calculi. He underwent left ureterolithotomy at which 3 stones were removed.

He was first admitted to U.C.H. in September 1968 at the age of 10 years exactly. His only additional history was a life-long nocturnal enuresis which was worse recently. Physical examination revealed no abnormality except his surgical scar and small stature (height on 5th centile, weight on 3 rd centile). His blood pressure was $120 / 85 \mathrm{~mm}$. Hg. Investigations at that time showed normal levels of haemoglobin, plasma urea, calcium, phosphorus, and electrolytes. Urine examination showed no abnormality, the 24-hour calcium excretion varied between 93-156 mg., magnesium 67-86 mg., and an amino acid chromatogram was normal. 24-hour urine oxalate excretion ranged between 56-93 mg. Radiology revealed a right lower ureteric stone and 2 small stones in the right kidney.

$\mathrm{He}$ was treated with magnesium hydroxide mixture $4 \mathrm{ml}$. t.d.s. and for a short period with added calcium carbimide $50 \mathrm{mg}$. b.d. No notable change in calcium or oxalate excretion occurred on this regimen. He was discharged for long-term follow-up taking magnesium hydroxide mixture (B.P.) $4 \mathrm{ml}$. t.d.s.

In the first 7 months after his discharge he suffered two attacks of urinary infection. He had one attack of renal colic followed by the passage of a stone in April 1969 , and passed one small stone without difficulty in
January 1970. He is otherwise well. Radiology has shown the appearance of new small stones, and his urine shows occasional red cells. Renal tubular acidosis has been excluded by a normal response to an ammonium chloride load.

\section{Discussion}

The biochemical basis of primary hyperoxaluria has recently been extensively reviewed by Williams and Smith (1968a), and will only be summarized here. There are two forms of the disease both of which are transmitted by an autosomal recessive gene. The metabolic block leading to oxalate overproduction in the commoner form (Type 1) is represented in Fig. 6. Koch et al. (1967) have shown the deficient enzyme to be $a$-ketoglutarate: glyoxylate carboligase. In addition to excess oxalate patients also excrete excess glycollic and glyoxylic acid (Hockaday et al., 1965). 6 of our patients (Cases 4-9) probably have this classic form. Williams and Smith (1968b) have recently described 4 patients with a genetic variant (Type 2), clinically indistinguishable from the main form, which is associated with L-glyceric aciduria instead of glycollic aciduria. The direct cause of hyperoxaluria in these patients is not fully understood. 3 of the 4 patients they studied are the sibs (Cases $1-3)$ described in more detail in the present report.

The natural history of primary hyperoxaluria has been summarized from the literature and described by Hockaday et al. (1964). Most of these cases have not been tested for L-glyceric aciduria but few would presumably have this rare variant. The disease usually presents with oxalate lithiasis in early childhood and runs a progressive course leading to death from renal failure before adult life. The uraemic phase is usually short and associated with a fall in urinary oxalate levels, which then leads to the deposition of oxalate crystals throughout the body, thus producing terminally the condition of oxalosis. A minority of patients may present with chronic renal failure.

The onset of symptoms occurs before the age of 5 in approximately $65 \%$ of patients, and $80 \%$ die before they reach the age of 20 . Prognosis is worse the earlier the age of onset. Rarely atypical cases may not present before early adult life and may run a relatively benign course. The possible benefit of any therapeutic regimen is difficult to assess since comparison with published series is restricted by the need to relate results not only to the age of onset but also to the length of follow-up. A further difficulty in assessing the prognosis of patients under observation arises from the restriction of the survey of Hockaday et al. (1964) to a record of whether the patients were alive or dead at the latest period of 


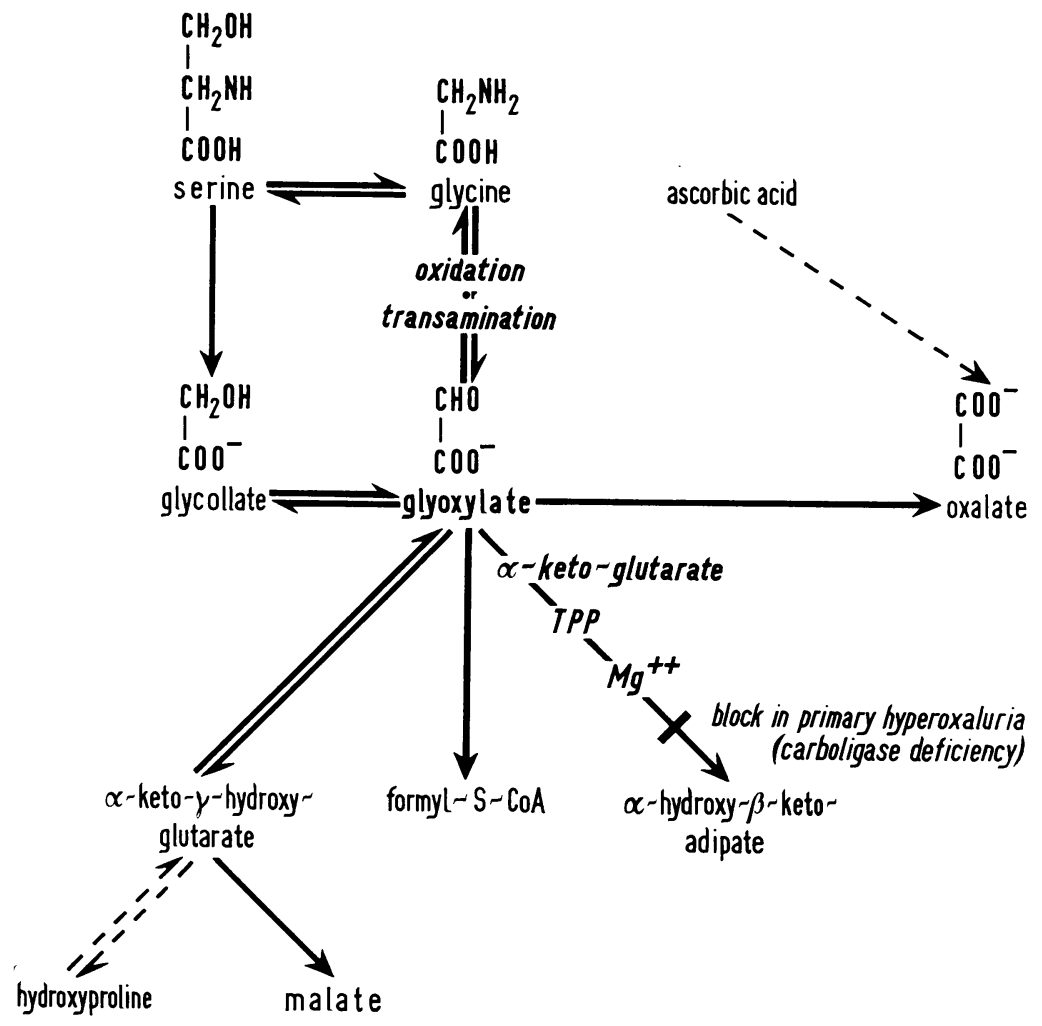

FIG. 6.-Pathways in oxalate synthesis. Modified from Smith and Williams, 1967.

follow-up. Thus of 40 typical cases presenting before the age of 5, $20(50 \%)$ had died after an average follow-up of 8 years (ranging from early death to living after 26 years). Of the 8 patients described by Hall, Scowen, and Watts (1960), 3 had died within 5 years of the onset of their first symptoms, and 2 were stone free and symptom free after 1 and 4 years.

By contrast all patients in the present series are alive and clinically well after an average period of 9 years since first presentation. First symptoms occurred before the age of 5 in 8 of our 9 patients and before the age of 3 in 7 . Only Case 4 was nearly adult before his first symptom and is thus atypical. Some of the data on these patients are summarized in the Table. They have all been under regular follow-up at intervals of 4 to 6 months since their first presentation, and at each attendance have had measurements of their 24-hour urine calcium, magnesium, and oxalate excretions.

Urinary oxalate in all our later studies after 1965 was measured by Dick's (1967) modification of the method of Archer et al. (1957); the normal range of daily oxalate excretion in 15 adults was $3-22 \mathrm{mg}$.
Results by this method agree closely with that of Hodgkinson and Zarembski (1961) which was mainly used earlier in this study. Hockaday et al. (1965) using an isotope dilution technique have shown that normal values in children are similar to adults when corrected for body surface area. The level of oxalate excretion in our patients does not appear to be related to the clinical course of the disease, a finding previously noted by Hall et al. (1960). Moreover it has fluctuated widely during follow-up, and twofold or even threefold changes have been found in consecutive specimens.

It is of interest that our two patients with nephrocalcinosis (Cases 1 and 7) have also had incomplete renal tubular acidosis (Wrong and Davies, 1959), as judged by defective urinary acidification after an ammonium chloride load. They were in fact first diagnosed and treated on this basis with sodium bicarbonate. Features suggestive of renal tubular acidosis have previously been noted in hyperoxaluria (Williams and Smith, 1968a). Thus the finding of renal tubular acidosis in a patient with nephrocalcinosis should not exclude a search for hyperoxaluria. 
TABLE

Clinical Details of Patients with Primary Hyperoxaluria, Dated to 1 January 1970

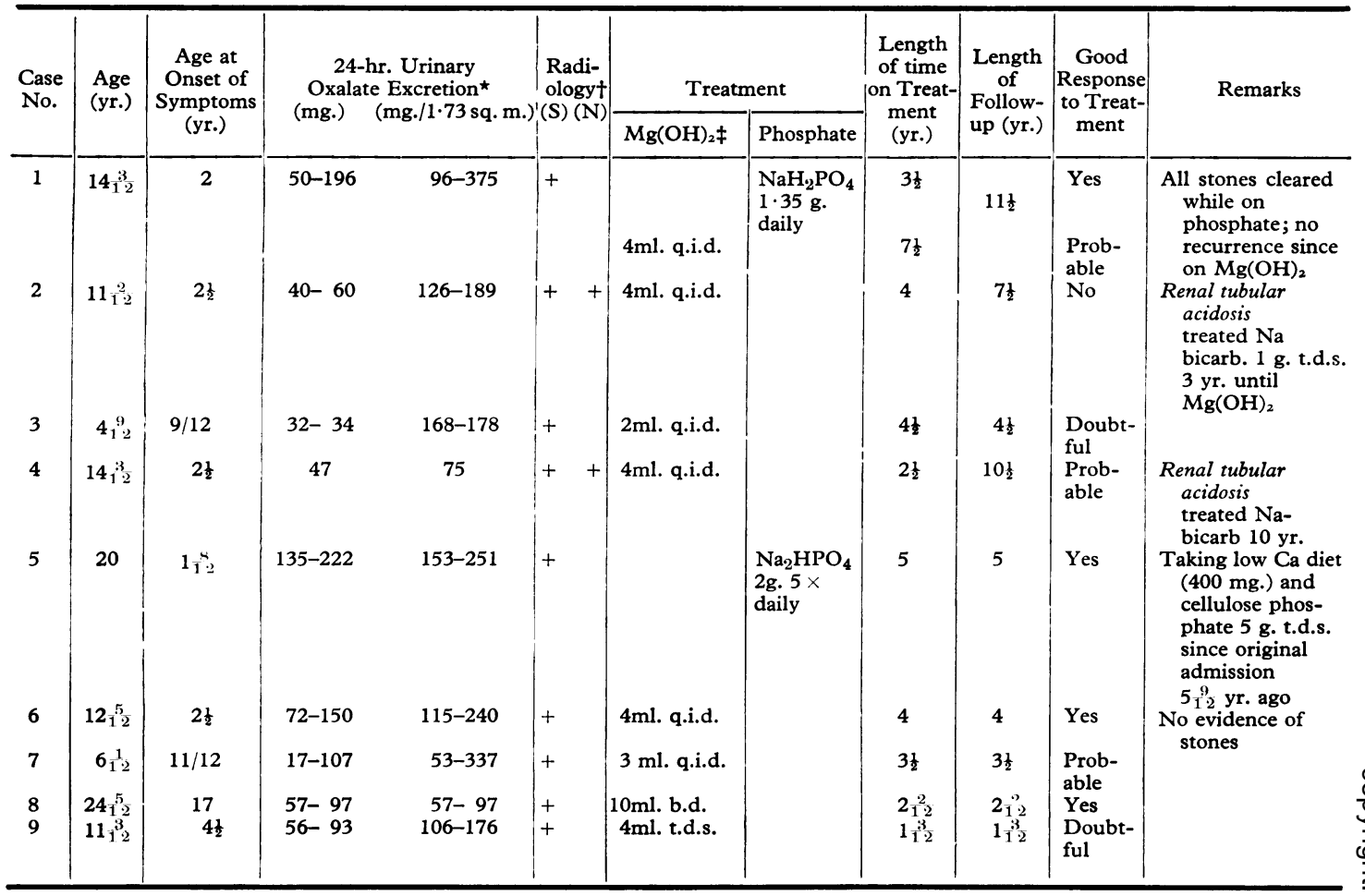

^Range during first U.C.H. admission.

†S $=$ stones, $\mathrm{N}=$ nephrocalcinosis.

$\ddagger \mathrm{Mg}(\mathrm{OH})_{2}$ as magnesium hydroxide mixture (B.P.).

The two main therapeutic approaches in primary hyperoxaluria have consisted of attempts either to diminish oxalate synthesis, and therefore excretion, by influencing its intermediary metabolism, or to alter the urine in such a way as to enhance calcium oxalate solubility at prevailing levels of oxalate excretion. The former approach has proved disappointing. Attempts have been made to reduce the availability of glycine, the major oxalate precursor, either by protein restriction or by benzoate administration to trap glycine as hippurate. Neither has met with long-term success (Archer et al., 1958; Swartz and Israels, 1963). The feeding of D-amino acids to compete with glycine for D-amino acid oxidase (glycine oxidase) has also been attempted without success (Smith and Williams, 1967); we gave D-L glutamic acid, 20-40 g. daily, to Case 9, without significant response. The same patient also received L-histidine on an empirical basis without effect. The aldehyde dehydrogenase inhibitor calcium carbimide was found by Solomons and his coworkers (Solomons, Goodman, and Riley, 1967) to lower oxalate excretion in one patient who received a kidney transplant, local irradiation, and corticosteroid therapy. However, no consistent effect was found during another study in three patients (Zarembski, Hodgkinson, and Cochran, 1967). Two of our patients (Cases 4 and 5) also received calcium carbimide ( $50 \mathrm{mg}$. b.d.) for 4 days without effect on oxalate excretion. Another aldehyde dehydrogenase inhibitor, tetraethylthiuram disulphide (disulfiram) was employed by Gibbs and Watts (1967) without effect, and our Case 4 also received the drug for 4 days without success. The administration of pyridoxine has been shown to reduce oxalate excretion both in certain groups of non-hyperoxaluric subjects (Gershoff, 1964) and in some patients with hyperoxaluria (Smith and Williams, 1967), but this has not been a consistent finding (Gibbs and Watts, 1967), and we have not been able to show an effect in one patient (Case 4) given the vitamin in the very large dosage of $100 \mathrm{mg}$. five times daily. On a purely empirical basis, we wondered if the administration of an intermediate, or derivative, of the tricarboxylic acid cycle would divert glyoxylate from oxalate synthesis. Malonate 
(1.5-3.0 g. daily) and valine, which is converted to methyl malonate ( $6 \mathrm{~g}$. daily), was administered to Case 3. Both compounds were without effect.* A major problem in short-term studies of oxalate excretion is the wide day-to-day fluctuation in urinary oxalate levels, which occurs even when diet, activity, etc. are closely standardized. This makes baseline determination very uncertain. Further understanding of this phenomenon could well lead to a more successful therapeutic approach.

We have followed the alternative line of treatment in our attempts to increase oxalate solubility in urine by the use of magnesium (in 8 patients) or phosphate ( 2 patients). Details are summarized in the Table. The presence of magnesium has long been known to prevent quantitative precipitation of calcium oxalate in vitro, and magnesium administration has more recently been found to inhibit oxalate stone formation in rats made hyperoxaluric both by pyridoxine deficiency (Lyon et al., 1966) and by ethylene glycol poisoning (Borden and Lyon, 1968-69). Combined pyridoxine and magnesium therapy has successfully prevented recurrent oxalate stone formation in patients not suffering from hyperoxaluria (Gershoff and Prien, 1967). Of our patients treated with magnesium hydroxide mixture (B.P.) in varying dosage (see Table), all are clinically well, 2 have improved, 3 have had all deterioration halted, and 3 show only minor radiological evidence of an increase in urinary tract calcification (Fig. 2-5).

A high phosphate intake has also been claimed to be of benefit in preventing urinary stone formation. This may be related in part to a decrease in urine calcium excretion, and in part to an increase in urinary levels of pyrophosphate and certain protective polypeptides (Howard and Thomas, 1968). Williams and Smith (1968a) 'have been greatly impressed ... . with its apparent efficacy in ... children with this serious disorder' (hyperoxaluria). While the present study reports the use of phosphate in only 2 patients with primary hyperoxaluria (Cases 6 and 9), both have appeared to benefit. In Case 6 complete disappearance of all renal calcification occurred over 3 years, and Case 9 has shown diminution of calcification while taking disodium hydrogen phosphate $(5$ g. t.d.s.) combined with a low calcium diet (less than $\mathbf{4 0 0} \mathrm{mg}$. daily) and cellulose phosphate $(5$ g. t.d.s.) to diminish intestinal calcium absorption.

Thus, while magnesium and probably phosphate

* Graphs of all the treatment trials are drawn in 15 figurss which have been deposited with the Librarian of the British Medical Association. Copies of these figures are available from him on application. treatment cannot be considered curative in primary hyperoxaluria, it does appear that with such management the previous gloomy prognosis in this condition may be improved. Longer follow-up of our patients is required for a final opinion.

We wish to thank Dr. Lloyd H. Smith for help in the original investigation of Cases 1 to 3 and Case 5 . He (with Dr. H. E. Williams) later rediagnosed Cases 1-3 as having oxaluria with L-glyceric aciduria. Dr. P. M. Zarembski kindly carried out the original oxalate determinations in these patients, Dr. M. Dick did the more recent determinations. One of us (T.S.) gratefully acknowledges receipt of a grant from the Medical Research Council.

\section{REFERENCES}

Archer, H. E., Dormer, A. E., Scowen, E. F., and Watts, R. W. E. (1957). Studies on the urinary excretion of oxalate by normal subjects. Clinical Science, 16, 405.

,,--- - (1958). The aetiology of primary hyperoxaluria. British Medical fournal, 1, 175.

Borden, T. A., and Lyon, E. S. (1968-69). The effects of magnesium and $\mathrm{pH}$ on experimental calcium oxalate stone disease. Investigative Urology, 6, 412.

Dick, M. (1967). A simplified urinary oxalate method. Proceedings of the Association of Clinical Biochemists, p. 186.

Gershoff, S. N. (1964). Vitamin $B_{6}$ and oxalate metabolism. Vitamins and Hormones, 22, 581.

- and Prien, E. L. (1967). Effect of daily $\mathrm{MgO}$ and vitamin $\mathbf{B}_{6}$ administration to patients with recurring calcium oxalate kidney stones. American fournal of Clinical Nutrition, 20, 393.

Gibbs, D. A., and Watts, R. W. E. (1967). Biochemical studies on the treatment of primary hyperoxaluria. Archives of Disease in Childhood, 42, 505.

Hall, E. G., Scowen, E. F., and Watts, R. W. E. (1960). Clinical manifestations of primary hyperoxaluria. Archives of Disease in Childhood, 35, 108.

Hockaday, T. D. R., Clayton, J. E., Frederick, E. W., and Smith, L. H., Jr. (1964). Primary hyperoxaluria. Medicine, 43, 315. , Frederick, E. W., Clayton, J. E., and Smith, L. H., Jr. (1965). Studies on primary hyperoxaluria. II. Urinary oxalate, glycolate, and glyoxylate measurement by isotope dilution methods. Fournal of Laboratory and Clinical Medicine, 65, 677.

Hodgkinson, A., and Zarembski, P. M. (1961). The determination of oxalic acid in urine. Analyst, 86, 16.

Howard, J. E., and Thomas, W. C., Jr. (1968). Control of crystallization in urine. American fournal of Medicine, 45, 693.

Koch, J., Stokstad, E. L. R., Williams, H. E., and Smith, L. H., Jr., (1967). Deficiency of 2-oxoglutarate: glyoxylate carboligase activity in primary hyperoxaluria. Proceedings of the National Academy of Sciences of the United States of America, 57, 1123.

Lyon, E. S., Borden, T. A., Ellis, J. E., and Vermeulen, C. W. (1966). Calcium oxalate lithiasis produced by pyridoxine deficiency and inhibition with high magnesium diets. Investigative Urology, 4, 133.

Smith, L. H., Jr., and Williams, H. E. (1967). Treatment of primary hyperoxaluria. Modern Treatment, 4, 522.

Solomons, C. C., Goodman, S. I., and Riley, C. M. (1967). Calcium carbimide in the treatment of primary hyperoxaluria. New England fournal of Medicine, 276, 207.

Swartz, D., and Israels, S. (1963). Primary hyperoxaluria. Fournal of Urology, 90, 94.

Williams, H. E., and Smith, L. H., Jr. (1968a). Disorders of oxalate metabolism. American fournal of Medicine, 45, 715.

- (1968b). I-Glyceric aciduria: a new genetic variant of primary hyperoxaluria. Newv England fournal of Medicine, 278, 233.

Wrong, O. and Davies, H. E. F. (1959). The excretion of acid in renal disease. Quarterly fournal of Medicine, 28, 259.

Zarembski, P. M., Hodgkinson, A., and Cochran, M. (1967). Treatment of primary hyperoxaluria with calcium carbimide. Nerv England fournal of Medicine, $277,1000$. 